\title{
De-construyendo identidades femeninas en el Ejército Nacional de Colombia: las mujeres militares ${ }^{1}$
}

\author{
https://doi.org/10.21830/9789585318304.01 \\ María Antonieta Corcione-Nieto ${ }^{2}$ \\ Escuela Militar de Cadetes "General José María Córdova” \\ Andrés Eduardo Fernández-Osorio ${ }^{3}$ \\ Escuela de Aviación del Ejército
}

\section{Resumen}

Aun cuando la identidad de los sujetos se conforma a partir de una gran clasificación genérica binaria representada en lo masculino y lo femenino, es evidente que no existe una feminidad esencial y única, sino que muchas veces las diversas formas de ser mujer no encajan en los modelos tradicionales construidos por la cultura (articulados en las relaciones sociales de desigualdad y poder entre los sexos). La identidad de las mujeres, en efecto, se concibe como el conjunto de características sociales, corporales y subjetivas que las identifican de manera real y también simbólica de acuerdo con la vida vivida. Así, este capítulo busca contribuir al debate contemporáneo sobre la carrera militar de mujeres en la dimensión subjetiva del género, la construcción y deconstrucción de las identidades femeninas; con lo cual se interpelan los roles establecidos tradicionalmente como masculinos y femeninos, que ahora transitan entre lo arquetípico y lo transgresor. Para ello, se recurre a la teoría de las prácticas de identidad con el fin de analizar la interacción entre lo femenino militar y la construcción de identidad.

Palabras clave: Ejército Nacional de Colombia; estudios de género; femenino; identidad; masculino; mujeres militares; roles

1 Este capítulo presenta los resultados del proyecto de investigación "Enfoques diferenciales en el Ejército Nacional: una propuesta desde las ciencias militares" del Grupo de Investigación en Ciencias Militares, de la Escuela Militar de Cadetes "General José María Córdova" (ESMIC), categorizado en B por Minciencias, código de registro COL0082556. Los puntos de vista y los resultados de este artículo pertenecen a los autores y no reflejan necesariamente los de las instituciones participantes.

$2 \mathrm{PhD}$ en Antropología (Universidad de los Andes). Magíster en Biología Humana (Universidad Autónoma de Barcelona). Líder del Grupo de Investigación en Ciencias Militares, de la Escuela Militar de Cadetes "General José María Córdova”. Orcid: https://orcid.org/0000-0002-3509-5519 - Contacto: maria.corcione@ esmic.edu.co

3 Teniente Coronel del Ejército Nacional de Colombia. PhD en Derecho y Ciencia Política (Universidad de Barcelona). Magíster en Economía, Estado y Sociedad: Política y Seguridad (University College London). Magíster en Relaciones Internacionales (Higher School of Economics, Moscow). Investigador del Grupo de Investigación en Aviación Militar de la Escuela de Aviación del Ejército. Orcid: https://orcid.org/00000003-0643-0258 - Contacto: andres.fernandez@buzonejercito.mil.co 


\section{Introducción}

Constituir un sujeto social —individual y colectivo - tiene como prerrequisito la consolidación de una identidad, de una conciencia de sí y de un sentido de sí mismo respecto a los demás (Valdés, 1995, p. 15). Esta construcción subjetiva de la identidad, considerada como un fenómeno subjetivo de elaboración personal y filtro cultural, se conforma a partir de una gran clasificación genérica dentro de un orden simbólico y un imaginario colectivo que constituyen escenarios tanto de la mujer y la feminidad como de los hombres y lo masculino en un mundo binario (Martínez Herrera, 2007). A lo largo del proceso de socialización, la identidad se nutre de la adscripción a grupos definidos por el ámbito de intereses, por el tipo de actividad, por la edad, el ciclo de vida y por todo lo que agrupa o separa a los sujetos en la afinidad o en la diferencia (Barbé, 1984; Lagarde, s. f.; Martínez, 1992).

Las mujeres, como género, comparten la misma condición histórica, pero difieren en sus situaciones particulares, en sus modos de vida y en la diversidad de sus experiencias según su clase social, su pertenencia regional, étnica o religiosa y sus concepciones del mundo, así como en los grados y niveles de participación y poder. Es por ello que se producen cambios en las maneras de ser/hacer mujer, de las que surge una diversidad de experiencias y manifestaciones identitarias (Arango et al., 1995).

Las identidades se constituyen y se construyen dentro de la representación y no fuera de ella. Las mujeres y los hombres aprenden roles de género impuestos por la educación e internalizados a lo largo de sus vidas. Dentro del imaginario social, las categorías bajo las cuales se construye la feminidad normativa están basadas en el modelo esposa-madre, pero dicho modelo ya no es suficiente para dar cuenta de la variedad de situaciones y roles de las mujeres actuales (Fuller, 1988). Hoy en día, una gran cantidad de mujeres ha quebrantado su rol tradicional femenino y ha logrado niveles de cualificación, experiencia profesional y protagonismo en el trabajo equiparables a los de los hombres (Ramos et al., 2003). Sin embargo, pese al ingreso de las mujeres tanto a la educación superior como al mercado laboral, culturalmente esto no ha significado para ellas el acceso completo al espacio de los hombres, pues aún en el espacio público del trabajo y la profesión se mantienen naturalizadas ciertas áreas y actividades como propias o no de las mujeres (Amorós, 1994).

La incorporación de las mujeres en las fuerzas militares, en igualdad formal con los hombres, ha sido uno de los cambios de adaptación contextual más importantes experimentados en las organizaciones castrenses contemporáneas (Duncanson \& Woodward, 2016; Moore, 2017), proceso que ha dado como resul- 
tado unas fuerzas militares muy plurales. Con un régimen disciplinario general para ambos sexos, las mujeres militares hoy en día desempeñan tareas idénticas y tienen las mismas responsabilidades y salarios que los militares varones (Agudo Arroyo, 2014). La experiencia de las mujeres en las fuerzas militares de diversos países ha sido investigada desde enfoques específicos de las ciencias sociales para identificar cómo la cultura militar percibe la participación de ellas, cómo ellas experimentan y reaccionan ante la cultura (hiper)masculina de los militares en diversos contextos internacionales y cómo, en ocasiones, se producen transformaciones de adaptación contextual dentro de las instituciones (véase, por ejemplo, Baechtold \& DeSawal, 2009; Carreiras, 2015; Daverio, 2009; Laurence et al., 2016; Zubieta et al., 2011). Para las Fuerzas Militares de Colombia, uno de los principales retos ha sido cómo proporcionar condiciones de equidad para las mujeres que libremente toman la decisión de ingresar a la vida de las armas (Latorre \& Fernández-Osorio, 2018; Zuluaga Ramírez, 2016), sin que el resto de los temas de análisis, en particular los relacionados con la identidad de género, se hayan agotado para comprender el fenómeno en su totalidad.

Aun cuando el papel desempeñado por las mujeres en las Fuerzas Militares colombianas había sido en campos logísticos y administrativos (Cuenca, 2011), la incorporación del primer grupo de mujeres como oficiales en 1976 y como suboficiales en el curso de armas del Ejército Nacional de Colombia en 1983 —en áreas como psicología, medicina, administración y derecho- (Camacho Zambrano, 2018) abrió el camino para la participación femenina en todas las actividades de defensa, integridad territorial, independencia y soberanía de la nación. Ante las demandas sociales de mayor apertura y enfoques diferenciales, mediante el establecimiento de nuevos perfiles ocupacionales, en 2009 se incorporaron las primeras mujeres que se graduaron como oficiales del cuerpo de las armas, al igual que sus pares masculinos (Camacho Zambrano, 2014).

Frente el panorama de apertura en busca de equidad, las posibilidades de ascenso de las mujeres del cuerpo administrativo en ramas del Ejército actualmente van hasta el grado de General, al igual que las mujeres oficiales del cuerpo de armas. En 2013, la primera mujer en llegar al rango de General hacía parte del cuerpo administrativo en la Justicia Penal Militar. Hoy en día, la segunda mujer en ascender al grado de General se desempeña como directora del Hospital Militar en Bogotá (ONU Mujeres, 2017). Como estos casos, los medios de comunicación siguen registrando historias de mujeres militares como las primeras en acceder a un cargo, las primeras en desempeñar una labor o las primeras en cumplir con las expectativas de aquello para lo que se capacitaron (por ejemplo, Comando General Fuerzas Militares de Colombia, 2019b, 2019e), mostrándolas como mujeres que por su 
compromiso, dedicación y total entrega cumplen un papel fundamental dentro de las Fuerzas Militares (Comando General Fuerzas Militares de Colombia, 2019a). Además, destacan su valentía y fuerza, factores que las llevan a ocupar lugares establecidos tradicionalmente como masculinos dentro de las instituciones militares, así como su abnegación, espíritu de sacrificio y firmeza para superar obstáculos y ganar batallas en las estructuras jerárquicas masculinas (Comando General Fuerzas Militares de Colombia, 2019c, 2019d).

Estas imágenes, que se convierten muchas veces en arquetípicas, entreabren cuestionamientos sobre la forma en que se considera y se espera que sea una mujer militar. Así, a medida que crece la población de mujeres militares en Colombia, es necesario examinar cómo estas han desarrollado y seguirán desarrollando su identidad de género dentro del Ejército Nacional, a partir de las teorías actuales de este campo pertinentes para el estudio de la experiencia de las mujeres en el cuerpo militar (Culver, 2013). En esta área de estudio se ha registrado una explosión discursiva en torno al término identidad, al mismo tiempo que se le ha sometido a una crítica minuciosa. La deconstrucción se ha realizado al interior de varias disciplinas, todas críticas de la noción de una identidad integral, originaria y unificada (Hall, 1996). Enmarcada en esta deconstrucción, la identidad de género es trabajada como una problemática transversal, cuyo análisis requiere una aproximación plurie interdisciplinaria, así como un cuestionamiento de las categorías binarias que prevalecen en el análisis social y el debate teórico de la modernidad: naturaleza/ cultura, público/privado, producción/reproducción, e incluso masculino/femenino (Alizade, 2007; Bonan \& Guzmán, 2007).

Frente a este panorama, el presente capítulo tiene como propósito problematizar la heterogeneidad y la multiplicidad, en especial, el carácter relativo y cambiante de las identidades de las mujeres y la vinculación de lo femenino con el escenario militar. Siguiendo a Castañeda-Rentería y Contreras (2017), este trabajo se acoge a la idea de que las identidades, como categorías analíticas, son una herramienta útil para el estudio de los sujetos sociales, pues a través de ellas es posible conocer y dar cuenta de los procesos mediante los cuales los individuos —en este caso, las mujeres - construyen y experimentan el ser mujer en un lugar y momento histórico determinado.

\section{Identidad de lo femenino: construcción y deconstrucción}

Las construcciones culturales que han dado pie a las representaciones de la realidad social y psicológica, así como del cuerpo, conforman lo que se ha deno- 
minado "sistema sexo/género" (Ramos et al., 2003). Este sistema es realmente una multiplicidad de sistemas articulados y dinámicos de relaciones de dominación/ subordinación que generan oportunidades diferenciadas para varones y mujeres según su cultura, etnia, condición social y orientación sexual. Se entiende por sistema sexo/género aquel conjunto de prácticas, símbolos, representaciones, normas y valores que las sociedades elaboran a partir de la diferencia sexual anatómica/fisiológica y que dan sentido a la satisfacción de los impulsos sexuales, a la reproducción de la especie humana y, en general, a las relaciones que las personas establecen entre sí. Estas convenciones conforman la trama social que condiciona las relaciones de los seres humanos en tanto personas sexuadas. Cada uno es semejante y diferente. Según los cuerpos, se proveen valoraciones jerarquizadas para hombres y mujeres y se les asigna roles distintos que provienen de prescripciones culturales sobre lo adecuado psicológica y socialmente (Jayme Zaro, 1999), con lo cual se configura el sentido para la construcción de las identidades genéricas (Olavarría, 2007).

Dentro de este sistema, la identidad se constituye a partir de varias dimensiones, en especial, desde la identidad personal —que se configura activamente a lo largo del tiempo y toma lo que considera necesario de la identidad asignada o aprendida - y desde la identidad internalizada — que constituye la identidad propia-. Ambas son transversales a lo social, lo corporal y lo subjetivo de manera real y simbólica en la articulación sexo/género.

La identidad siempre está en proceso constructivo, no es estática ni coherente, no se corresponde mecánicamente con los estereotipos. Cada persona reacciona de manera creativa al resolver su vida, y al resolverse, elabora los contenidos asignados a partir de su experiencia, sus anhelos y sus deseos sobre sí misma. (Lagarde, 2000, p. 61)

Dado que el concepto de identidad no es esencialista, sino estratégico y posicional, repercute sobre el análisis de lo femenino, de las condiciones sociales e históricas que definen y transforman las identidades sociales de género, de las representaciones sociales, la ideología y la cultura que buscan dar sentido a la diferenciación sexual. La categoría de género ${ }^{4}$ permite diferenciar diversas aproximaciones

4 Introducido en la década de los sesenta, el concepto de género viene a cuestionar una serie de supuestos sobre el sexo, es decir, sobre la creencia (profundamente arraigada) de que la pertenencia a uno u otro sexo es el fundamento de la identidad o, en otras palabras, de la experiencia de sentirnos masculinos o femeninos. El reconocimiento de los contenidos que superan lo fisiológico fue promovido inicialmente desde movimientos culturales, especialmente el de liberación femenina, que planteó una reflexión general sobre el papel tradicional de la mujer en la sociedad y la estructura familiar, reflexión que se hizo extensible a los roles de género en general (Jayme Zaro, 1999). Por tanto, el concepto de género ha de articularse, pero no confundirse, con el de sexo (San Miguel, 2015). 
a la identidad femenina. En tanto identidad de género, lo femenino se presenta como una construcción social y cultural, variable, histórica y transformable, que se distingue del sexo biológico. Es por ello que se admite la problematización de la identidad de género en las interrelaciones entro lo femenino y lo masculino (Arango et al., 1995).

La feminidad, como la masculinidad, es contingente y cambiante en tanto producción histórico-cultural, aunque existen algunas constantes trans-históricas. Indudablemente, se han producido cambios y avances en la situación familiar, laboral, política y social de las mujeres, y en las relaciones entre los sexos en las sociedades desarrolladas, vinculados con modificaciones en las representaciones de la mujer y la feminidad; no obstante, persisten modelos e ideales que inciden negativamente en la vida de las mujeres. (Tubert, 2010, p. 162)

Es así como las representaciones de lo femenino actúan como modelos que influyen en los sujetos en contraposición a lo masculino $0^{5}$. A lo largo de la historia, ha sido posible identificar cierta versión de feminidad que se erige en norma y deviene en hegemónica, de forma que se incorpora en la subjetividad tanto de mujeres como de hombres en un proyecto patriarcal (Olavarría, 2007). Pese a las variaciones históricas de la mayoría de las sociedades conocidas, la construcción social y simbólica de la diferencia sexual está fundada en la representación binaria de lo masculino y lo femenino (Bonan \& Guzmán, 2007).

En esta dicotomía, se ha caracterizado el modelo masculino como centrado en metas instrumentales. La masculinidad implica reconocerse a sí mismo como ambicioso, individualista, dominante, fuerte y dispuesto; mientras que las expectativas de la feminidad están centradas en el área afectiva e intersubjetiva. Lo femenino implica definirse como un ser dulce, tierno, afectuoso, compasivo y discreto (Jayme Zaro, 1999). Adicional a esto, se encuentra el mandato de cuidar a los otros cercanos y vulnerables, mandato que hace recaer sobre lo femenino la responsabilidad del sostenimiento de los vínculos, bajo la amenaza de la culpa que aparece si las relaciones se deterioran o se interrumpen (San Miguel, 2015).

5 Siguiendo a Kimmel (1997), la masculinidad está conformada por un conjunto de significados cambiantes atravesados por una constante: la construcción histórico-social de la virilidad, que tiene lugar en oposición a las mujeres y a las minorías sexuales y poblacionales. Por tanto, la masculinidad es ante todo la huida de lo femenino. La identidad masculina nace de la renuncia de lo femenino, no de la afirmación directa de lo masculino a partir de la construcción de atributos propios. Dentro de esta masculinidad, persiste la masculinidad hegemónica, planteada por Connell (1995), y usada para referirse a un tipo de identidad masculina que coincide con la posición social de superioridad de los hombres heterosexuales. El poder configurador de la masculinidad hegemónica se hace evidente en la vida de los hombres, no tanto en su discurso como en sus prácticas, en su identidad representacional, pero esencialmente en la funcional (Bonino, 2002). 
Esta representación social de ser mujer se ha instituido en norma (Mateos Sillero, 2013), toda vez que señala lo que le está permitido y prohibido y lo que debería formar parte de su identidad. Con esto, se busca regular al máximo las relaciones genéricas, de acuerdo con el esquema de percepciones de un orden simbólico interiorizado ${ }^{6}$. Estas representaciones son transmitidas por la familia y otras redes sociales mediante procesos de identificación, con lo que se configura el estereotipo dentro de los sistemas culturales de los diferentes grupos sociales.

En cuanto a las representaciones modernas de lo femenino, estas son estudiadas desde las ciencias sociales, que han identificado un estereotipo en el que lo femenino funciona como algo probado y, por tanto, se habla del eterno femenino ${ }^{7}$ como arquetipo (Gómez \& Perdomo, 1993). Este arquetipo circunscribe la feminidad a rasgos morfológicos y psicológicos que definen a la mujer. Igualmente hace referencia a conductas públicas y privadas que se consideran sistemáticas para los individuos de sexo biológico femenino y se estigmatizan socialmente las que se aproximan al sexo biológico masculino. Por tanto, lo que llamamos femenino (caricatura, como todo estereotipo, basada en el arquetipo de la feminidad) se asocia también al cuerpo de la mujer (Jiménez, 2008). El arquetipo femenino conjuga los estereotipos designados a la personalidad, referidos a conductas de rol, referidos a profesiones y a la apariencia física (Deaux \& Lewis, 1984). Como lo plantean Bonan y Guzmán, "la diferencia sexual, el sexo biológico, pasa a ser considerada una cuestión real concreta e irreducible y el género un fenómeno determinado por la realidad biológica de los cuerpos" (2007, p. 3).

Pero esa cosa llamada feminidad es muy diversa y, por consiguiente, lo femenino no existe como entidad única e inmutable, absolutamente limitada por la biología. En consecuencia, no existe lo que se ha llamado la esencia femenina ${ }^{8}$, como

6 Aunque el objetivo aquí no es presentar las diferentes caracterizaciones de lo femenino que se han establecido a lo largo del tiempo, uno de los aspectos identitarios que más se destaca es el discurso social sobre la maternidad. Desde la teoría feminista se ha revelado el carácter construido de la maternidad: se ha demostrado que el imaginario social que la sostiene, además de identificarla con la feminidad, ha generado un ideal de cumplimiento que se supone común a todas las mujeres (Saletti Cuesta, 2008).

7 El eterno femenino, obra de tres actos escrita por Rosario Castellanos, presenta la deconstrucción del género como arquetipo, tanto desde la perspectiva de la mujer moderna en lo cotidiano, como desde la antigua creación de los mitos de la mujer, iniciando con Eva (una Eva muy sarcástica, incrédula y tímida) (Sieber, 1999). En cada uno de los actos se van evidenciando distintos niveles de la sociedad de consumo, hasta ir penetrando en el meollo principal de la mujer individual versus su imagen superpuesta. La autora hace notar que la mitificación de la mujer en distintos roles es una consecuencia de la necesidad colectiva de preservar la imagen femenina y aplicarla a la manipulación social (Fox-Lockert, 1982). La deconstrucción del género como arquetipo en $E l$ eterno femenino implica el estudio de la interacción de los estereotipos colectivos de la cultura de masas y la ideología política, particularmente, en relación con el patriarcado y la validez de este (Sieber, 1999).

8 La esencia femenina se concibe como una identidad mítica, una condición innata que atraviesa y constituye a todas las mujeres (Sánchez de Bustamante, 2014). Para Joan Rivière (1929), la idea de la feminidad 
tampoco existe algo así como la "experiencia masculina" o la "experiencia femenina” esencial, en general y en abstracto. Como categoría analítica, el género es un universo complejo que desborda los límites del pensamiento binario. Por ello, desde la perspectiva de una teoría crítica de lo social, el género permite no solo indagar para comprender, sino visibilizar para deconstruir las relaciones asimétricas que están en la base de las estructuras sociales, así como en las estructuras mismas de los hombres y de las mujeres. Gracias a la categoría del género, es posible menoscabar los dispositivos de la lógica de la dominación de la civilización occidental (Cabral \& García, 2005). Por ello, la masculinidad y la feminidad, en última instancia, son experiencias íntimas y profundamente subjetivas (Martínez Herrera, 2007).

Considerando así la experiencia femenina, cabe señalar que el interés aquí es abordar las dicotomías presentadas desde lo arquetípico hasta lo transgresor de lo femenino. A partir de ello, se explora la experiencia de ser mujer, mediada por la manera en que histórica y simbólicamente se ha construido la diferencia sexual que ha producido lo femenino y lo masculino, particularmente, desde un escenario hipermasculinizado como es el campo militar.

\section{Identidad militar femenina: entre estereotipos y contraestereotipos}

La identidad profesional está profundamente marcada por la dimensión del género. El proceso de socialización fomenta el desarrollo de actitudes asociadas a la identidad femenina, que en algunos casos puede ser negativa para la promoción y el éxito laboral. Cuando una persona realiza la elección de sus estudios y va desarrollando su carrera profesional, numerosos procesos de género están actuando, repercutiendo no solo en la dirección que toma, sino también en el nivel de compromiso e implicación laboral (Ramos et al., 2003). Como consecuencia, el trabajo profesional desde lo público es uno de los organizadores más importantes de la identidad femenina actual, instaurada a partir de la apreciación de que cada vez un grupo más grande de mujeres laboralmente activas invierten y ocupan un tercio de su tiempo diario en el espacio público?. De esta forma,

\footnotetext{
como construcción, como máscara — no como una especie de marca de nacimiento que prevé nuestro destino, imposible de borrar u ocultar - es lo que se concibe como femenino. No se trata de la esencia de la mujer, sino de una especie de performance social susceptible de transformarse (Senabre Llabata, 2014).

9 El acceso de las mujeres a la educación universitaria tiene dos momentos. En el primero, unas pocas accedieron de manera excepcional o disfrazadas de hombres; y en el segundo, se produce el acceso de la mujer (como género) de manera sistemática. Este último momento estuvo enmarcado en un contexto de crecientes
} 
la profesión o el trabajo se constituyen en un espacio mucho más habitado por mujeres (Castañeda-Rentería \& Contreras, 2017).

En el campo institucional se crean, como lo define Barbé (1984), identidades institucionales atribuidas y concebidas como las imágenes que los otros disponen de sí mismos; en este caso, identidades autoasignadas por individuos o colectivos pertenecientes a estas mismas instituciones. Estas representaciones, que llegan a ser el fundamento de la identidad institucional, pueden resultar contradictorias con la identidad personal. En esta dinámica de construcción y deconstrucción de identidad, se contienen representaciones colectivas, representaciones compartidas por otros; como ya se expuso, la identidad contiene esferas de identidad compartida. Aun conservando una cierta autonomía, el concepto de identidad colectiva ${ }^{10}$ no debe ser separado del concepto basilar de identidad.

Dentro de estas esferas identitarias, la identidad de género se configura como un sistema cultural de significado que organiza la vida social. Dado que esta última se entiende como un entramado de las vidas personales, interpersonales y comunitarias, no puede ser separada de la esfera de las organizaciones como las militares. Los ejércitos se han caracterizado históricamente por ser sistemas muy tradicionales y de estructura rígida (Gómez Escarda, 2009). La vida castrense es una ocupación históricamente colmada de estereotipos custodiados por argumentaciones que suscitaban en el imaginario colectivo la imagen del hombre guerrero frente a la de mujer-madre (Martín Martínez, 2009). Este imaginario se ha constituido en una

reclamos y luchas feministas por la igualdad de derechos a inicios del siglo XIX. Empezó en Estados Unidos, continuó en las décadas siguientes en Europa y, hacia fines de siglo, llegó a América Latina. La primera carrera universitaria de la que egresaron la mayoría de mujeres fue medicina, tal vez porque la medicina y el cuidado era concebido como natural para las mujeres, dentro de cuyos conocimientos del hogar estaba la higiene y la salud (Palermo, 2002). Esta primera carrera dio acceso a especialidades de las ciencias de la salud vinculadas con el cuidado y permitió la participación de las mujeres en carreras consideradas típicamente femeninas, como las ciencias de la educación y las humanidades. Aún en el siglo XX, seguía existiendo la histórica diferenciación de carreras femeninas (psicología, odontología y ciencias sociales) y carreras masculinas (matemáticas e ingenierías), que reforzaban la identidad de hombres y mujeres. Con la gradual feminización de la educación, las carreras masculinas empezaron a ser elegidas por mujeres, sin que esto haya significado en muchos casos un futuro profesional en igualdad de condiciones. Como argumenta Gaña (2008): “la anticipación de lo que ellos y ellas pueden esperar del mundo real de oportunidades, condiciona sus opciones, sobre un fondo de creencias y autopercepciones diferenciales según género internalizadas desde los primeros ańos de la socialización familiar y escolar" (p. 85).

10 Se debe aclarar, como lo hace Grimson (2010), que la identidad y la cultura no son nociones iguales. Cultura alude a nuestras prácticas, creencias y significados rutinarios, fuertemente sedimentados por nuestra tradición; mientras que la identidad se refiere a nuestros sentimientos de pertenencia a un colectivo. En este caso, a un colectivo establecido dentro del sistema sexo/género. Por tanto, no siempre las fronteras de la cultura coinciden con las fronteras de la identidad. Puede ser que, dentro de un grupo social del cual todos sus miembros se sientan parte, no necesariamente exista homogeneidad cultural. 
identidad colectiva ${ }^{11} \mathrm{y}$, en muchos casos, en una identidad profesional polarizada en el sistema sexo/género. Este paradigma se establece en la medida en que los miembros de la cultura militar fusionan sus identidades organizacionales (colectivas) e individuales en una imagen externa coherente que reafirma la esfera de lo público, a pesar de la heterogeneidad de lo institucional militar y el cruce de esferas identitarias que se intersecan (De Andrade Júnior \& Prouse, 2018). A raíz de esto, las identidades personales entran en confrontación con los estereotipos culturales, que son el punto de referencia constante. Esta feminización ideológica de determinadas actividades y ocupaciones reproduce el rol tradicional femenino ligado al cuidado en relación con las diferencias biológicas (Agudo Arroyo, 2014).

Aunque la institución militar ha basado y establecido su identidad desde la idea de masculinidad ${ }^{12}$; de acuerdo con Titunik (2000), también es una institución que disminuye la importancia de las características primordiales y personales y crea una condición de solidaridad comunitaria que trasciende las distinciones individuales. En teoría, tal solidaridad es consistente con este prerrequisito de la cohesión de la unidad, en la que la autoridad militar se establece de acuerdo con el rango y no con la persona (ni sus características personales e identitarias) ${ }^{13}$. Las mujeres, entonces, han sido asimiladas en un ambiente institucional intrínsecamente conectado con la masculinidad, pero hipotéticamente neutral a las cualidades personales del otro (Titunik, 2000). Ciertamente,

Los militares, como categoría social, se definen en términos de inclusión, debido a una identidad construida de manera sólida y constante con su imagen externa, en especial porque es transmitida mediante agentes de comunicación que son expertos en el uso simbólico. Y artificialmente, a través de ellos, la sociedad consigue informarse de lo que hacen los militares o lo que deberían ser. (De Andrade Júnior \& Prouse, 2018, p. 14)

11 Se debe aclarar que no es en ningún modo obligatorio que todos los sujetos que contribuyen a la formación de un actor colectivo compartan plenamente todos los componentes de una misma identidad colectiva (Barbé, 1984).

12 Tradicionalmente, la guerra se ha considerado un asunto de hombres. Más aún, la figura del guerrero ha constituido un referente primordial de identidad en la socialización masculina infantil, donde características como la fortaleza, el valor, la agresividad y la osadía han representado sinónimos de virilidad y la hombría (Londoño, 2005).

13 De acuerdo con King (2013), es precisamente esta cohesión basada en la competencia profesional y no en valores culturales arbitrarios la que ha permitido en las Fuerzas Armadas del Reino Unido que minorías étnicas, religiosas y colectivos LGBTI hayan podido servir en las diversas fuerzas. Este autor recalca que la rescisión de las restricciones estadounidenses al servicio militar de homosexuales ha enfatizado en la cohesión de las tareas —-lo impersonal y lo profesional—, sobre la cohesión social. 
Aun cuando existe una identidad colectiva sólida, las relaciones de género masculino/femenino han sido definidas y reproducidas en el discurso organizacional militar desde categorías de identidades genéricas o arquetípicas, macro- o histórico-temporales, las cuales "no se refieren a un fenómeno complejo que se produce con características particulares en la personalidad de los sujetos individuales sino a la identidad del hombre/mujer tradicional o del hombre/mujer de la sociedad moderna o posmoderna” (Barbé, 1984, p. 75). Es así como estas identidades arquetípicas han respondido a los cambios en la identidad masculina y femenina a lo largo de diversos contextos históricos, aunque de manera menos cambiante para el caso de las mujeres frente al de los hombres.

A lo largo de la historia, la presencia femenina como integrante de fuerzas bélicas ha producido construcciones típicas (estereotipos de mujeres guerreras), a partir de mujeres que han desempeñado papeles relevantes en los ejércitos. Tales estereotipos se han agrupado en cuatro grupos: 1) figuras próximas al mito que representa la resistencia, la heroicidad y la inspiración en la causa que se defiende; 2) líderes que comandan ejércitos enteros o unidades concretas, ya sean masculinas, mixtas o femeninas; 3) mujeres que, debido a la secular tradición masculina de los ejércitos, se enlistan en estos haciéndose pasar por hombres; y 4) mujeres que se incorporan en ejércitos regulares sin ocultar su propia condición y son consideradas con los mismos criterios que los hombres (Martín Martínez, 2009).

Dicha presencia se puede fácilmente calificar como desacostumbrada, puesto que las normas jurídicas y sociales no han permitido una mayor presencia activa de las mujeres en los ejércitos hasta bien entrado el siglo XX [...] en Latinoamérica: Chile en 1995; Uruguay y Honduras en 1997; Perú en 1998; Ecuador y El Salvador en 2000; Venezuela en 2001 y Paraguay en 2003 [...]. Sí que resulta novedoso, y especialmente característico de los tiempos actuales, la aparición y consolidación de iniciativas (y) esfuerzos orientados a permitir una integración real de las mujeres en las Fuerzas Armadas, introduciendo así, de hecho, la perspectiva de género en los cuarteles. (Martín Martínez, 2009, p. 31)

En las dinámicas de profesionalización de las fuerzas militares, las discusiones sobre la inclusión de las mujeres como parte de las instituciones castrenses se han suscitado en diversas esferas. Los escépticos temen que la presencia de mujeres en los ejércitos pueda obstaculizar la eficiencia de una organización que consideran más apropiada para los hombres; mientras que los defensores afirman que se debe dar igualdad de oportunidades a las mujeres que sirven dentro de las filas. Estas dos posturas no necesariamente son contradictorias o excluyentes (Hong, 2002). Aunque la postura de los escépticos pierde fuerza, los diversos gobiernos no parecen 
contrarios a que las mujeres desempeñen en sus fuerzas militares funciones tradicionalmente propias de ellas, pero es en materia de combate (una tarea denominada como masculina) donde más reacios se han mostrado a incluir mujeres en sus filas (Lence Reija, 1995). Dentro de los factores encaminados a lograr la inclusión y la igualdad de las mujeres frente a los hombres se encuentra la perspectiva de género, que, como proceso, exige cambios graduales en una institución que no ha estado acostumbrada a una equidad de géneros. No obstante, estos debates tienden a ignorar la perspectiva de las propias mujeres militares (Sasson-levy, 2003).

Aunque el debate teórico sobre la participación de las mujeres en las fuerzas militares no es novedoso, sí ha tenido un giro al analizar, primero, el mantenimiento de las operaciones de paz y la participación de las mujeres militares en ciertas vías específicas como las operaciones de consolidación y mantenimiento de paz, contrainsurgencia y estabilización luego de la guerra fría; y segundo, el ingreso de mujeres cada vez mayor a las fuerzas militares para cursar y disfrutar carreras en estas instituciones (Duncanson \& Woodward, 2016). El nexo género-militar necesita comprenderse y dar cuenta de ese hecho, mientras permanece alerta para contribuir a los objetivos feministas de igualdad de género, paz y justicia en equidad (Moore, 2017).

De acuerdo con el feminismo de corriente más liberal y con una aproximación empírica, los dilemas sobre la inclusión de las mujeres en lo militar, particularmente en roles de combate, no han estado en el centro de la discusión (King, 2013). Si las mujeres son o no capaces de asumir roles militares no es importante para el análisis, sino más bien si las mujeres deben buscar inclusión dentro de las filas, al tenor de la pregunta si este sería un progreso para las mujeres y el feminismo (Goldman, 1982; Carter, 1996). Desde la década de los setenta, el debate se ha llevado a cabo entre dos posiciones políticas opuestas. Por un lado, están quienes defienden el "derecho a luchar", haciendo hincapié en la igualdad de las mujeres con los hombres. Por otro lado, están las feministas antimilitaristas, que argumentan que la participación militar de las mujeres simplemente legitima una institución, lo que es antitético a los objetivos propios del feminismo (Duncanson \& Woodward, 2016).

Silva (2008) se cuestiona si presentar mujeres de combate pone en primer plano la cuestión central sobre las posiciones de las mujeres en las fuerzas armadas. Se permite cuestionar si el Ejército (en este caso, el norteamericano) brinda oportunidades para el empoderamiento de las mujeres, con lo que ofrece un escape frente a las normas de género de la sociedad civil restrictivas, o esta institución, con su estructura e historia profundas de género, simplemente explota la retórica del empoderamiento para utilizar el trabajo de las mujeres, al mismo tiempo que privilegia la masculinidad y reproduce la ideología de género tradicional. 
Para Wills (2005), cuando las mujeres ingresan a las filas de instituciones armadas no están ni traicionando su naturaleza femenina ni quedando subyugadas ante la lógica patriarcal, sino que están infringiendo barreras construidas por una mirada masculina que les asignó imperativamente el ámbito doméstico y de cuidado como el terreno de su realización, siempre bajo la mirada proteccionista masculina. Un comienzo de superación de los estereotipos femeninos se alcanza cuando las mujeres transgreden fronteras y se abren camino hacia espacios antes vedados a su presencia.

De muchas formas, el contexto militar puede verse como un potenciador de empoderamiento para las mujeres, pues ofrece un escape a las normas de género impuestas desde las identidades genéricas binarias, pero su estructura e historia de género privilegia la masculinidad y reproduce la ideología tradicional de género. Las mujeres pueden convertirse en guerreras (Lence Reija, 1995), sin embargo, puede ser cuestionada la forma en que las mujeres militares adoptan comportamientos y características tradicionalmente no femeninas y aún conservar sus identidades como mujeres, como ellas mismas. No obstante, establecer un género en formas culturalmente reconocibles es crucial para la concepción más profunda de uno mismo, así como la forma esencial de tener interacciones importantes con otros (Silva, 2008).

Sin que la cuestión se haya zanjado, los esfuerzos investigativos han estado enfocados a comprender por qué, aunque existe una mayor participación de mujeres en las instituciones militares, esta sigue siendo problemática, ya que no alcanza la cuota de participación representativa. Un factor particular que ha afectado la participación de mujeres en el ejército es la necesidad de navegar en la cultura masculina. Las mujeres deben superar el estereotipo de que tradicionalmente no deben matar o ser violentas, o sea, que no pueden ser soldados (DeGroot, 2007). Además, debido a que los militares enfatizan que la unión masculina es esencial para la cohesión de grupos pequeńos, las mujeres se ven obligadas a emplear estrategias como acentuar demasiado o subestimar su feminidad para redefinir su género y así asimilarse en la cultura militar (Rosen et al., 2003). En este contexto de identidades genéricas, las mujeres deben navegar en una cultura en la que no saben si es posible equilibrar la identidad de un guerrero, un miembro del ejército, con una identidad femenina, sin comprometer una u otra (Herbert, 1998).

Bem (1983) afirma que aunque la mayoría de las personas desarrollan un esquema de género durante la primera infancia, cuando las mujeres ingresan en empleos dominados por hombres — como los militares—, deben aprender a redefinir lo que significa ser mujer. Esto se debe a que en la educación militar se forja 
un sujeto institucional al mismo tiempo que un sujeto masculino (Pérez Bravo, 2011); la conformación de sujetos femeninos, entonces, entra en disputa al no tener un espacio de desarrollo propio en términos de igualdad. En este sentido, Frutos Balibrea (2009) expone:

La igualdad como valor heredado de la modernidad constituye el marco de referencia de los roles de género. Este valor fue trasladado desde la moral a la política. La cuestión es si en las Fuerzas Armadas el debate entre diferencia / desigualdad entre hombres y mujeres se resuelve en términos de equidad. Las mujeres al entrar a un espacio definido absolutamente como masculino tienen que enfrentarse a un problema de identidad y a procesos de aculturación. Desde una dimensión subjetiva de la igualdad podríamos decir que nadie quiere ser "otro", en todo caso, "ocupar el lugar del otro", en este caso las mujeres aspirarían a ser "como hombres" sin dejar de ser mujeres. Pero también la incorporación de mujeres interpela a los hombres porque dejan de tener un espacio exclusivo y la institución empieza a convertirse en algo híbrido. (pp. 260-261)

En este aspecto, Herbert (1998) encontró que las mujeres en el ejército se sienten presionadas para manejar su identidad de género, por tener que enfatizar sus cualidades femeninas o masculinas para ser soldados exitosos. En su estudio encuentra que algunas mujeres sintieron que necesitaban actuar de manera más femenina para asegurarse de que aún eran vistas como una mujer real (idealizada), mientras que otras sentían la necesidad de actuar más masculinas para asimilarse mejor en la cultura militar. Reforzando este argumento, Cuadrado (2004) encuentra que las mujeres, para funcionar como líderes, deben presentar características contraestereotípicas, ya sea asemejándose a los hombres que ejercen el mismo rol que ellas y distanciándose de los estereotipos de las personas de su mismo género o llegando al extremo de la hiperfeminización para la consecución de beneficios.

Siguiendo esta idea, Höpfl (2003) plantea que la incorporación al cuerpo militar se logra a través de la cancelación de lo femenino. Las mujeres pueden ser juguetes o cuasihombres; de cualquier manera, son desmembradas para mantener el buen orden dentro de la institución. No obstante, su análisis no se refiere a los choques físicos entre hombres y mujeres, sino al choque entre ideas de sexualidad. Para ser miembros de la institución militar las mujeres deben tener un pene metafóricamente. Al convertir a las mujeres reales y sus cuerpos físicos en meras representaciones, el poder disruptivo del cuerpo femenino se neutraliza y se hace seguro. Es irónico que la adquisición del falo así representada se interprete como un triunfo del feminismo. Para Höpfl (2003), las organizaciones militares no parecen ser un lugar para las mujeres con cuerpos físicos que producen sangre menstrual, 
leche materna, olores maternos; las mujeres solo pueden ser admitidas en formas representativas, en formas arquetípicas.

En 2009, Benedict entrevistó a múltiples mujeres que indicaron una pérdida de feminidad en el ejército. Atribuyeron esta pérdida a varias cosas, como el uniforme unisex de los militares, la necesidad de mantener su cabello de cierta manera, el poco maquillaje y la falta de accesorios que puedan demarcar feminidad o gusto por la moda. Ya que el cuerpo constituye el frente de inscripción de identidad más inmediato (Ayús Reyes \& Eroza Solana, 2007), al desligarlo del estereotipo y diluirlo en el mundo de lo "sin sexo" despoja a las mujeres de su identidad anterior al mundo militar. Tras el análisis de las experiencias de las mujeres en el ejército, este estudio demostró que muchas de ellas se ven obligadas a adoptar una identidad de género genérica (masculina), que no es natural para ellas, pues deben recurrir a enfatizar sus rasgos femeninos o masculinos.

Igualmente, Agudo Arroyo (2014) encuentra que en España la igualdad en las Fuerzas Armadas ha ganado terreno; sin embargo, existen resistencias, sobre todo, por parte de la población masculina, en la que sobrevive una mentalidad tradicional acerca de los roles de cada género. "No solo entre los varones que hacen referencia al empleo que hacen sus compañeras, para su propio beneficio, de las 'armas de mujer', sino también entre algunas mujeres que usan la "debilidad" para obtener privilegios en el trabajo" (Agudo Arroyo, 2014, p. 15). En ocasiones, se ven abocadas a asumir comportamientos masculinos como propios, en un proceso de aculturación o de transformación de su identidad, con el fin de no ser menospreciadas por los compańeros de profesión y estar por fin en el terreno de lo igualitario.

El caso venezolano presenta un escenario complejo. Según Moreno Orta (2013), las reiteradas prácticas discursivas militaristas han impuesto como hegemónico en el resto de la sociedad un imaginario simbólico de lo militar en la violencia, en torno al cual los procesos de identificación colectiva han asignado un modelo de interpretación del mundo androcéntrico. La manera como se ha establecido en el imaginario social venezolano la cultura militar fundada en lo heroico y la guerra ha traído consigo una representación de la política como ejercicio masculino y guerrero, consolidado en las representaciones sociales normativas hegemónicas de género. En el seno de la Fuerza Armada venezolana persisten normativas hegemónicas masculinas y una concepción dicotómica de género, además resaltan elementos de jerarquización social en cuanto a las características femeninas.

Pérez Bravo, realiza en 2011 un estudio sobre la identidad militar en el Ejército de Chile. Su investigación encuentra que uno de los marcadores identitarios de la educación militar son los simbolismos que caracterizan la masculinidad tradicional, 
lo cual implica cuerpos fuertes, resistentes y capaces de dominarse y dominar. Por tanto, convertirse en militar exige el control y represión de las emociones que reflejen temor o debilidad ${ }^{14}$. "El proceso de formación militar — despersonalizado, indiferenciado y homogeneizante - se inspira en un sujeto normativo abstracto que estaría por encima de los sujetos reales, sean estos hombres o mujeres. [...] Esto problematiza el que las mujeres puedan ser representantes de este universal" (p. 180).

En esta búsqueda de igualdad, algunas mujeres transgreden su identidad para ajustarse a la norma masculina y, así, ser reconocidas como pares y validadas como iguales, o bien sufren su identidad, pues le atribuyen un significado inferior desde una relación jerárquica de subordinación. Sin embargo, como anota Pérez Bravo (2011), este discurso a favor de la igualdad de género en el que se pone en circulación la lógica de méritos individuales, cuando se trata de mujeres, entra en contradicción. Las cadetes son abordadas de modo indiferenciado como parte de la categoría mujer para efectos de distribución de oportunidades de acceso, trabajo y diseño de la trayectoria laboral. Las mujeres son remitidas a una versión universal y esencialista de la mujer, una versión arquetípica. En este sentido, el modelo de identidad femenina se relaciona con la versión que, para reproducirse, excluye lo masculino.

La educación militar, de trato indiferenciado, tensiona y disloca la identidad tradicionalmente entendida como "femenina", en cuanto a las normas y modos de expresión, llamándoles a suprimir aquellas expresiones acordadas socialmente como "de mujeres". El conflicto es visible en la necesidad de negar parte de lo "femenino". Parecen entonces, obligadas a masculinizarse en términos de volverse fuertes, mantener control y dominio para insertarse y convertirse en militares. (Pérez Bravo, 2011, p. 185)

Ahora bien, sin que la revisión de casos presentada haya sido exhaustiva, se observa que, aunque desempeñar roles de género de manera reconocible culturalmente es crucial para la concepción de uno mismo (así como para formar interacciones significativas con los demás), cuando las mujeres militares adoptan comportamientos y características tradicionalmente no asociadas a lo femenino esperando conservar sus identidades como mujeres — como ellas mismas—, sus acciones son puestas en duda. Si bien las prácticas identitarias reflejan una agencia

14 A lo que se denomina soldado, en este punto, corresponde a una categoría arquetípica: aquellos preparados física y psicológicamente para la resistencia, la asertividad y el mando de tropas. Este diseño lleva más de cien ańos centrado en la morfología masculina, así como en otras características asociadas con lo masculino en contraposición a lo "femenino" (Camacho Zambrano, 2014). 
humana capaz de negociación, transformación y renovación, siempre son limitadas y condicionadas por la estructura de las relaciones sociales. Por esta razón, las mujeres militares se han representado como sujetos que se mueven entre dos opuestos identitarios relacionados con el sistema genérico binario.

Siguiendo la tesis de Sasson-Levy (2003), las mujeres soldados en roles masculinos adoptan identidades discursivas y corporales características de los soldados hombres que significan tanto resistencia como complacencia al orden genérico militar. Estas prácticas subvierten el régimen militar de género binario tradicional, ya que las mujeres se niegan a aceptar definiciones militares de feminidad y masculinidad como identidades esencialmente dicotómicas, por lo cual transitan entre ellas. Ahora bien, al mismo tiempo, la adopción de la identidad masculina por parte de las mujeres puede interpretarse no como una subversión, sino como colaboración con las normas androcéntricas militares.

Así pues, al entender desde una visión normativa el género, es decir, solo percibido como una experiencia natural, la idea de mimetización y alineación de colocarse una máscara detrás de la cual las mujeres siguen siendo otras diferentes a las que aparentan (Daverio, 2009) — toma relevancia y se fundamenta. No obstante, desde los enfoques identitarios, la identidad no es algo que se logra o no, sino que se considera como uno de los componentes de la dimensión subjetiva de la acción. En esta dinámica subjetiva de construcción-deconstrucción, mantener un sentido de identidad femenina requiere de las mujeres militares la transposición de definiciones civiles de feminidad — que han asumido y conocido durante toda su vida — al ámbito militar, incluso cuando estas definiciones se oponen directamente a los valores de la cultura militar.

\section{Más allá de las historias femeninas que rompen esquemas: mujeres militares colombianas}

En 1976 se dio el primer paso institucional para permitir la incorporación de mujeres en el Ejército Nacional de Colombia. En dicho año, doce mujeres lograron el ingreso al escalafón militar como oficiales administrativas con especialidades en medicina, odontología, arquitectura, derecho, bacteriología, administración y educación (ONU Mujeres, 2017). No fue sino hasta 2009 que ingresó a la Escuela Militar de Cadetes “General José María Córdova” la primera promoción de cadetes mixta conformada por 62 mujeres, de las cuales se graduaron 48 en diciembre de 2011, quienes podrán acceder al grado de General desde distintas armas (Camacho Zambrano, 2018, pp. 39-40). 
De acuerdo con Camacho Zambrano (2011), el ingreso de este primer grupo de mujeres coincidió con el proyecto para establecer el sistema educativo de las Fuerzas Armadas, articulado con la formación en derechos humanos y derecho internacional humanitario. Alineada con estas primeras acciones encaminadas a la igualdad entre hombres y mujeres, en 2015 se establece la Directiva Permanente n. ${ }^{\circ} 30$, que busca la equidad de género para las mujeres de las Fuerzas Militares, garantías y respeto de sus derechos; así como la Directiva Permanente $20151110000277-M D N-C G F M J E M C-$ SEMCFJI-JEDHDIH-23.1 (Comando General de las Fuerzas Militares, 2015), en la que se fijan los lineamientos estratégicos para las Fuerzas Militares en equidad de género, enfoque diferencial y prevención de violencia basada en género.

Estas disposiciones, al igual que las necesidades de la Fuerza, han permitido graduar hasta el momento mujeres de las Armas en Aviación, Inteligencia, Ingenieros, Comunicaciones, Artillería, Caballería y del Cuerpo Logístico en las especialidades de Transportes, Armamento e Intendencia (Ministerio de Defensa, 2018). Aunque este es un logro importante para la inclusión de la mujer uniformada dentro de sus filas, así como en sus escenarios y cargos de toma de decisiones en seguridad y defensa, existen aún percepciones limitantes en cuanto al rol de la mujer en el Ejército y la proyección de su identidad social como mujer militar (Fernández-Osorio \& Latorre-Rojas, 2018b).

Sumándose a las discusiones de los diversos ejércitos del mundo occidental sobre el papel que deben tener las mujeres en la institución castrense, en particular, la pertinencia que podrían tener en la línea de operaciones, campo reservado para los hombres (Zuluaga Ramírez, 2016), en Colombia el debate se ha dado en diferentes niveles sociales y gubernamentales. Las discusiones se han enmarcado en que la participación de las mujeres rompe con estereotipos y, por tanto, cuestiona y trasciende el precepto de que la guerra es y ha sido una cosa de hombres. Los que están en contra señalan que la participación femenina debe estar limitada a asuntos administrativos, no operativos, porque, aunque la guerra tiene un importante componente tecnológico y requiere apoyo logístico, continúa siendo un asunto que requiere fuerza y destreza física; algo que, según este tipo de opciones, la mujer no posee (ONU mujeres, 2017).

Superado el hermetismo del Ejército Nacional con relación a las disposiciones de socialización, los estudios para comprender la participación de mujeres en las instituciones militares han comenzado por saber quiénes son, de dónde vienen y qué esperan de su carrera militar. Los esfuerzos se han centrado, primero, en caracterizar la población estudiantil de la Escuela Militar de Cadetes "General José María Córdova” (Fernández-Osorio et al., 2018) y, segundo, en interpretar la 
construcción del rol de la mujer militar, entre otros temas (Fernández-Osorio \& Latorre-Rojas, 2018a).

Para el caso del análisis de identidades en el Ejército Nacional, los estudios se han aproximado a la propuesta que expone la caída del orden institucional, en la que se apunta que, a raíz de la globalización, ya no hay posibilidad de mantener sistemas integrados de creencias, por lo que es necesario concentrarse en el sujeto militar como objeto de estudio (Corcione Nieto \& Cabrera-Cabrera, 2018). Este proceso apunta a la pérdida de vigencia de las instituciones para dar lugar a que los individuos piensen su vida, se proyecten en ella y comprendan su situación en el sistema mundo ${ }^{15}$ (Pérez Bravo, 2011).

En este constructo teórico de lo que se llama identidad militar femenina, los estudios realizados por Camacho Zambrano $(2011,2014$, 2018) para el Ejército colombiano muestran que se encuentra en proceso la construcción de las mujeres como agentes políticos y como sujetos militares. Se parte del hecho de que la educación militar impartida en la Escuela Militar de Cadetes "General José María Córdova" actualmente no tiene restricciones para la elección del arma, dado que todos los estudiantes reciben el mismo modelo de formación. Como resultado de este esquema de homogenización, se asume un fenómeno de neutralización de las identidades de lo femenino y lo masculino y se instaura una identidad única y totalitaria: la identidad militar. En esta dinámica, las mujeres adoptan una identidad social de género que minimiza los rasgos femeninos y asume como propias las conductas que enmarcan lo militar asociadas con lo masculino (Fernández-Osorio \& Latorre-Rojas, 2018b).

En consecuencia, el papel de las mujeres en el Ejército Nacional sigue siendo contradictorio debido al esencialismo de género para la disposición de armas, ya que, por un lado, se asume la igualdad y, por el otro, en la práctica y proyección laboral futura, se les considera útiles únicamente en labores administrativas y de oficina. Aunque esta contradicción no se expresa de manera directa, sí se evidencia la existencia de condiciones estructurales sutiles y a la vez determinantes que restringen tanto a hombres como a mujeres en ciertas posiciones de sujeto — para este caso, femenino- de las cuales es muy difícil salir (Camacho Zambrano, 2014).

15 El concepto sistema mundo "surgió como contrapartida al primer eurocentrismo, que pensó que Europa, desde sus pretendidos orígenes griegos y medievales latinos, produjo desde dentro los valores, los sistemas instrumentales que se universalizaron en los últimos cinco siglos, en el tiempo de la modernidad" (Dussel, 2004, p. 202). Aquí se sigue a Marcus (2001) desde la ola de capital intelectual de lo posmoderno que sale de los lugares y situaciones locales de la investigación etnográfica convencional, al examinar la circulación de significados, objetos e identidades culturales en un tiempo-espacio difuso. 
En medio de esta dicotomía, la construcción de la identidad militar por parte de las mujeres entra en una lucha constante que gira en tono a conceptos esencialistas (opuestos en el campo binario). El comportamiento definido como propio de un género se fundamenta, para el caso colombiano, en lo tradicional-conservador, con la naturalización de la división de tareas con base en el género y con la asunción del dimorfismo biológico como el estándar de lo que se considera masculino y femenino. Las mujeres militares adoptan —al igual que muchas en ambientes hipermasculinizados - lo que Camacho Zambrano (2014) denomina géneros performativos, "los cuales describen comportamientos y simbolismos asociados con el manejo del cuerpo que son reconocibles por el entorno y atribuibles a un género específico como la delicadeza o la fuerza, la ternura o la vulgaridad, entre otras, que se establecen así como polos por los cuales se perciben las actitudes de una persona" (p. 106). En el entorno militar, lo performativo se asocia a lo masculino. Esto lleva a que se refuercen actitudes y comportamientos de lo masculino, a pesar de que el discurso oficial enuncie ecuanimidad para los géneros en el Ejército.

En esta dinámica de coerción de la Fuerza, las mujeres buscan mecanismos para integrarse y ser parte del todo —en este caso, del todo masculino- - que para Camacho Zambrano (2018) se denomina la masculinidad femenina. En esta lucha por pertenecer, las mujeres establecen procesos de imitación que luego deben ser desligados (tanto en el ámbito militar como en el civil), ya que se sancionan socialmente si no son lo suficientemente femeninas.

Las mujeres se enfrentan a una doble exigencia dentro del Ejército y muy seguramente en mucho otros oficios, y es la de ser tan competentes como un hombre en todas las actividades pero además conservar su feminidad que se valora básicamente en su capacidad de seguirse viendo delicadas y hermosas. La mayoría de las mujeres de la ESMIC acepta este imperativo social con agrado, desean verse lindas y continuar siendo delicadas, dos virtudes que nunca se han considerado útiles para el oficio militar [...]. A estas clases de protocolo y etiqueta militar se les suma a las mujeres algunas clases de glamour, donde se les enseña cómo maquillarse, vestirse, peinarse para ceremonias y reuniones, también se les enfatiza en algunas formas de saludar, caminar y hablar que les permita conservar su delicadeza y feminidad. (Otálora Parra, 2015, p. 85)

Como se observa, es aquí donde las mujeres que hacen parte de este espacio masculino, al ver que su mímesis es infructuosa para su integración y legitimación, aceptan la fase del esencialismo estratégico ${ }^{16}$ de la hiperfeminización establecida

16 El concepto de esencialismo estratégico permite comprender los procesos mediante los cuales las mujeres - para el caso que plantea Martínez Cruz, las mujeres indígenas — se constituyen como sujetos en 
institucionalmente (Camacho Zambrano, 2014). De acuerdo con esta postura, las mujeres hacen a un lado determinada identidad u otra en función de la adaptación a la institución militar que está estructurada sobre lo masculino (como hegemónico-conservador). Esta adaptación identitaria no tiene otro fin que buscar la cohesión y la pertenencia a la institución, es decir, se trata del manejo de las identidades relacionales más que de las identidades categóricas que siguen intactas en este juego de ocultamiento.

\section{No solo existen identidades femeninas contradictorias: existen múltiples mujeres militares}

Pensar la identidad femenina en ambientes institucionalizados sobre la base estereotipada de lo masculino — tanto en su expresión corporal, hábitos y costumbres como en su configuración cultural y organizacional— no es un camino fácil ni de trayectoria unilineal. Esto es así, debido a que la esencia de lo castrense, además de estar constituida históricamente por soldados hombres motivados por su masculinidad, deja por fuera la construcción de lo femenino (esencialista o no) como elemento que pueda interactuar en esta relación. De hecho, la masculinidad fue y es un factor motivador clave que alienta la solidaridad en los integrantes de la institución, cuyas lógicas obedecen al código del soldado de combate (King, 2013).

Desde lo público, lo militar y la acción militar se han visto como el escenario y el trabajo de los hombres. No obstante, los cambios producidos por la guerra y los cambios en los roles y las vidas femeninas de la sociedad contemporánea han transformado la percepción cultural de la participación de las mujeres en la vida militar (Torres-Reyna \& Shapiro, 2002), como se ha evidenciado a lo largo del texto.

A pesar de ello, en el contexto suramericano sigue vigente el debate de si permitir o no personal femenino en especialidades relativas al combate. Estas discusiones guardan relación con el paradigma de masculinidad hegemónica, que refuerza la visión de la superioridad de unas características de género sobre otras (Moreno Orta, 2013). "Las actitudes hacia la mujer, la integración de la mujer en la profesión militar, las oportunidades que tienen en las academias militares, los problemas de relación con el sexo dominante y la ausencia de estándares de

contextos específicos politizando sus identidades. Este esencialismo evidencia un interés político, en cuyo marco se acepta temporalmente una posición esencialista de identidad, que no es la expresión de una esencia, sino un recurso o capital político para posicionar ciertos sectores o intereses (Martínez Cruz, 2016). 
evaluación específicos por género que conducen a la discriminación comenzaron a estudiarse a comienzos de los años 80" (Lupano et al., 2008, p. 198).

Sin que se haya llegado a una determinación sobre este tema, el ingreso de mujeres a las instituciones militares sigue realizándose sin que se encuentre claridad acerca de las características identitarias que se espera de ellas. Ante el poco entendimiento de la participación femenina (en todas las dimensiones sociales), los elementos de concepción de identidad se definieron a partir de concepciones polares, es decir, dualidades absolutas, en donde la identidad de un grupo se definía solamente en contraste y en oposición a otros, lo que acercaba a la comprensión de un fenómeno más bien descriptivo, reductible a la suma de sus rasgos definitorios (Portal Ariosa, 1991). De esta manera, se estructura la idea de una mujer militar como un tipo único que se mueve en dos polos opuestos.

A raíz de esto, las nuevas propuestas investigativas exploran la identidad como la articulación de una historia personal y una tradición sociocultural. Como se ha expresado, el imaginario hegemónico del género es un potente motor en la construcción de las identidades individuales, tanto de hombres como de mujeres, así como en la formación de subjetividades colectivas de gran impacto en la vida social. Ambas, subjetividades colectivas e identidades de género, se constituyen a través de procesos de estructuración provistos y sustentados en la memoria social que incluye reminiscencias, actitudes y sentimientos, reglas sociales, normas, patrones cognitivos, conocimiento científico y tecnológico (Bonan \& Guzmán, 2007). De acuerdo con este enfoque,

no se pueden pasar por alto los roles, las presiones situacionales y las definiciones impuestas y heredadas de la realidad social. En tanto se reconoce que la identidad es una combinación de propiedades comunes a un grupo de actores, pero que también debe referirse a las propiedades individuales que se dan dentro de esas combinaciones, y que en su construcción median las instituciones y los roles, la perspectiva permite dar cuenta sobre la dialéctica entre lo social y lo individual y los elementos intermedios que median su relación. (Pérez Bravo, 2011, p. 173)

De manera que las identidades, como productos sociales, dotan de sentido a las propias interacciones sociales que, como tales, son resultado de la organización social del sentido, es decir, de la cultura (Giménez, 2007). Por ello, para poder hablar de qué es ser/hacer mujer, como sujeto social e individual, siempre será imprescindible la discusión de la categoría de género.

En este sentido la utilidad de la categoría de género es amplia, implica no solamente el modo como la simbolización cultural de la diferencia sexual afecta las relaciones 
entre hombres y mujeres, sino también como estructura la política, la economía, el sistema jurídico legal, las instituciones del Estado, la vida privada, la intimidad, las ideologías, las ciencias y otros sistemas de conocimiento, etc. (Bonan \& Guzmán, 2007, p. 2)

Con ello se puede afirmar que el concepto de identidad social es una construcción inseparable de la concepción sociológica y antropológica que se tiene del sujeto social, la cual está constantemente en proceso de reformulación y transformación (Portal Ariosa, 1991). En definitiva puede decirse, como lo plantea San Miguel (2015), que la identidad no es unitaria sino poliédrica, y que, del conjunto de sus atributos, cada persona se siente (de manera subjetiva) más definida por unos $\mathrm{u}$ otros rasgos de identidad nacional, religiosa, de clase o racial. La impronta de dichos modelos de identificación tiene variaciones histórico-culturales y variaciones individuales. Por consiguiente, la identidad femenina se encuentra en un cauce de indeterminación cuando es pensada como una construcción en la cual el orden simbólico es variable (Martínez, 1992).

De acuerdo con lo que propone Silva (2008), debido a que nuestra cultura legitima la identidad de género solo cuando es percibida y experimentada como natural, mantener un sentido de identidad parecería requerir que las mujeres transpongan las definiciones civiles de feminidad que han conocido toda su vida al contexto militar, incluso cuando estas definiciones permanecen en oposición directa a los valores de la cultura tradicional militar. De este modo, se podría argumentar que las mujeres tienen imágenes más ambiguas y conflictivas, un material más complejo a partir del cual construir la noción de sí mismas, lo cual no se puede conciliar fácilmente con las definiciones de realidad masculina (Höpfl, 2000).

Así, pues, esta lucha constante de construcción y deconstrucción de la(s) identidad(es) ha permitido que dentro de las Fuerzas Militares se haya ido configurando y multiplicando un sujeto femenino militar que emerge en un marco de búsqueda de igualdad de derechos como sustento básico de interacción para llegar a una relación de espacios equitativos. En este camino, este sujeto militar femenino ha transgredido las identidades genéricas binarias asumidas por parte de las instituciones castrenses, lo que le ha permitido diluirse entre identidades opuestas para presentarse como un sujeto social que debe ser comprendido.

\section{Reflexiones finales}

Pensar la identidad como proyecto es ubicarla en el lugar de la búsqueda. No hay un fin a cumplir ni un lugar preciso al que llegar, lo que hace que se 
construya y deconstruya desde múltiples experiencias y pluralidades. El fin está ligado a la experiencia propia y relacional, producto de la construcción misma en los contextos histórico-culturales. Siendo así, la identidad femenina debe ser tratada como resultado de las experiencias de las mujeres y como una construcción. En este punto, se debe cuestionar lo femenino definido en contraposición a lo masculino, para reinventar (desde ellas mismas) lo femenino y el ser mujer, de forma que su experiencia se inscriba como referente primordial en la construcción de una nueva y siempre mutante identidad.

A través de lo expuesto, se ha podido entrever que no todas las identidades femeninas están para revolucionar los roles de género dentro de las Fuerzas Militares. Algunas de ellas se verán como constructoras activas de identidades significativas que resistan la hegemonía de lo masculino en lo militar, otras simplemente asumirán su experiencia femenina y el quehacer de ser mujer militar como una adscripción natural.

Es por eso que ampliar las narrativas de la identidad femenina, deconstruyendo el arquetipo de lo femenino y de lo femenino militar, y dándole paso a la construcción de nuevas identidades femeninas —en plural—, permitirá reconocer que más allá de los perfiles institucionales — de mujeres abnegadas y sacrificadashay mujeres reales con una identidad particular. Las Fuerzas Militares colombianas deben abrirse a la construcción y al establecimiento de la igualdad de posibilidades y derechos, más que a la búsqueda de la equivalencia, para convertirse en un eje real de transformación social.

A partir de este nuevo reto, es necesaria la profundización de los análisis desde las realidades académicas para deconstruir las dicotomías de lo femenino-masculinizado, lo masculino y lo hiperfemenino. De esta forma es posible identificar evidencias para cuestionar el carácter natural de las relaciones inequitativas entre géneros y comprender cómo se reproduce, se resiste o incluso se transforma el género de hombres y mujeres en el ámbito militar en Colombia. Puesto que las identidades tienen contenidos y detrás de ellas hay roles ligados a las posiciones sociales, étnicas y culturales, cabe tener presente siempre la pregunta: ¿De qué mujer militar estamos hablando?

\section{Referencias}

Agudo Arroyo, Y. (2014). La participación de las mujeres en las Fuerzas Armadas españolas: de la incorporación a la integración. Comunitaria. Revista Internacional de Trabajo Social y Ciencias Sociales, 7, 9-27. https://doi.org/10.5944/comunitania.7.1 
Alizade, M. (2007). Reflexiones sobre género y feminidad. Revista GPU, 3(4), 450-455.

Amorós, C. (1994). Feminismo, igualdad y diferencia. UNAM-PUEG.

Arango, L. G., León, M., \& Viveros, M. (1995). Introducción. En L. G. Arango, M. León, \& M. Viveros (Comps.), Género e identidad. Ensayos sobre lo femenino y lo masculino. Ediciones Uniandes; Universidad Nacional de Colombia; Tercer Mundo Editores.

Ayús Reyes, R., \& Eroza Solana, E. (2007). El cuerpo y las ciencias sociales. Revista Pueblos y Fronteras, 2(4), 1-56. https://doi.org/10.22201/cimsur.18704115e.2007.4.217

Baechtold, M., \& DeSawal, D. (2009). Meeting the needs of women veterans. In R. Ackerman, \& D. DiRamio (Eds.), Creating a Veteran-Friendly Campus: Strategies for transition and success. Jossey-Bass.

Barbé, C. (1984). Identidad e identidades colectivas en el análisis del cambio institucional. Revista de Estudios Politicos, 37, 67-87.

Bem, S. L. (1983). Gender schema theory and its implications for child development: Raising gender-aschematic children in a gender-schematic society. Signs, 8(4), 598-616.

Benedict, H. (2009). The lonely soldier. The private war of women serving in Iraq. Beacon Press.

Bonan, C., \& Guzmán, V. (2007). Aportes de la teoría de género a la comprensión de las dinámicas sociales $y$ los temas especificos de asociatividad y participación, identidad y poder. Centro de Estudios de la Mujer CEM.

Bonino, L. (2002). Masculinidad hegemónica e identidad masculina. Dossiers Feministes, 6, 7-36.

Cabral, B., \& García, C. (2005). Masculino/Femenino... ¿Y yo? Identidad o identidades de género [Preprint]. Repositorio de la Universidad de Los Andes. http://www.saber.ula.ve/handle/123456789/16351

Camacho Zambrano, C. M. (2011). Políticas de equidad de género en las Fuerzas Armadas. Impactos en la cultura institucional militar: el caso de la incorporación de cadetes femeninas en la ESMIC. Revista Cientifica General José María Córdova, 9(9), 69-93. https://doi. org/10.21830/19006586.246

Camacho Zambrano, C. M. (2014). Ejército, feminidades y género performativos: las experiencias de ser mujer y militar en la Escuela General de Cadetes "General José María Córdova” [Tesis de maestría, Pontificia Universidad Javeriana]. Repositorio de la Universidad Javeriana. https://bit. ly/3hIZuU7

Camacho Zambrano, C. M. (2018). Caleidoscopio. Estudios sobre feminidades y perspectiva de género en el contexto militar colombiano. Escuela Militar de Cadetes "General José María Córdova". https://doi.org/10.21830/9789585200838

Carreiras, H. (2015). Gender and civil-military relations in advanced democracies. Res MilitarisWomen in the Military, 1, 1-18.

Carter, A. (1996). Should women be soldiers or pacifists? Peace Review, 8(3), 331-335.

Castañeda-Rentería, L., \& Contreras, K. (2017). Apuntes para el estudio de las identidades femeninas. El desafío entre el modelo hegemónico de feminidad y las experiencias subjetivas. Intersticios Sociales, 13, 1-19.

Comando General de las Fuerzas Militares. (2015). Directiva Permanente 20151110000277-MDN -CGFM-JEMC-SEMCFJI-JEDHDIH-23.1. Lineamientos estratégicos para las Fuerzas Militares en equidad de género, enfoque diferencial y prevención de violencias basadas en género. Comando General Fuerzas Militares. 
Comando General Fuerzas Militares de Colombia. (2019a). Cinco mujeres entre los 500 hombres del Batallón de Desminado Humanitario. https://www.cgfm.mil.co/es/blog/cinco-mujeres-entre-los-500-hombres-del-batallon-de-desminado-humanitario

Comando General Fuerzas Militares de Colombia. (2019b). Oficial Fuerza Aérea, distinguida con el más importante premio nacional de ciencia en Colombia. https://www.cgfm.mil.co/es/blog/ oficial-fuerza-aerea-distinguida-con-el-mas-importante-premio-nacional-de-ciencia-en-colombia

Comando General Fuerzas Militares de Colombia. (2019c). Héroes Bicentenarios serán certificados en explosivos y demoliciones. https://www.cgfm.mil.co/es/blog/heroes-bicentenarios-seran-certificados-en-explosivos-y-demoliciones

Comando General Fuerzas Militares de Colombia. (2019d). Conozca a las primeras cuatro mujeres escoltas de la Fuerza Aérea Colombiana. https://www.cgfm.mil.co/es/blog/conozca-lasprimeras-cuatro-mujeres-escoltas-de-la-fuerza-aerea-colombiana

Comando General Fuerzas Militares de Colombia. (2019e). Teniente de Navío Piloto es la primera mujer Comandante del Patrullero Marítimo CN 235. https:/www.cgfm.mil.co/es/blog/ teniente-de-navio-piloto-es-la-primera-mujer-comandante-del-patrullero-maritimo-cn-235

Connell, R. (1995). Masculinities. Polity Press.

Corcione Nieto, M. A. y Cabrera-Cabrera, L. (2018). Identidad e ideología: dinámicas culturales entre los estudiantes de la Escuela Militar de Cadetes. En A. Fernández-Osorio, \& E. LatorreRojas (Eds.), La construcción del rol de la mujer militar (pp. 41-65). Escuela Militar de Cadetes "General José María Córdova" .

Cuadrado, I. (2004). Valores y rasgos estereotípicos de género de mujeres líderes. Psicothema, 16(2), 270-275.

Cuenca, Y. (2011). La participación de algunas mujeres en el Ejército Nacional de Colombia. Revista la Manzana de la Discordia, 6(2), 57-63.

Culver, V. (2013). Woman-warrior: Gender identity development of women in the American Military. Journal of the Indiana University Student Personnel Association, 64-74. https://scholarworks. iu.edu/journals/index.php/jiuspa/article/view/3674/3376

Daverio, A. (2009). Exploraciones en torno a la integración de las mujeres y las relaciones de género en instituciones policiales. Prácticas de Oficio. Investigación y Reflexión en Ciencias Sociales, 4, 1-9.

De Andrade Júnior, H. y Prouse, T. (2018). Complejidad cultural e imagen institucional: ¿Cómo se comunican los militares? Revista Escribania, 21(16), 13-34.

Deaux, K. \& Lewis, L. L. (1984). Structure of gender stereotypes: Interrelationships among components and gender label. Journal of Personality and Social Psychology, 46(5), 991-1004. https:// doi.org/10.1037/0022-3514.46.5.991

DeGroot, G. J. (2007). A few good women: Gender stereotypes, the military and peacekeeping. International Peacekeeping, 8(2), 23-28. https://doi.org/10.1080/13533310108413893

Duncanson, C., \& Woodward, R. (2016). Regendering the military: Theorizing women's military participation. Security Dialogue, 47(1), 3-21. https://doi.org/10.1177/0967010615614137

Dussel, E. (2004). Sistema mundo y “transmodernidad”. En S. Dube, I. Banerjee, \& W. Mignolo (Coords.), Modernidades coloniales: otros pasados, historias presentes (pp., 201-226). El Colegio de México. 
Fernández-Osorio, A., \& Latorre-Rojas, E. (2018b). Perfil sociodemográfico de los futuros oficiales del Ejército Nacional de Colombia. En A. Fernández-Osorio, \& E. Latorre-Rojas (Eds.), La construcción del rol de la mujer militar (pp. 13-39). Escuela Militar de Cadetes "General José María Córdova”.

Fernández-Osorio, A., \& Latorre, E. (2018a). La construcción del rol de la mujer militar. Escuela Militar de Cadetes "General José María Córdova”.

Fernández-Osorio, A., Latorre-Rojas, E., \& Mayorga-Zarta, N. (2018). The 2018 Colombian Military Academy dataset: A sociological study of population. Revista Cientifica General José María Córdova, 16(23), 147-162. http://dx.doi.org/10.21830/19006586.345

Fox-Lockert, L. (1982). El eterno femenino en la obra de Rosario Castellanos. En G. Bellini (Coord.), Actas del Séptimo Congreso de la Asociación Internacional de Hispanistas (pp. 461-466). Bulzoni Editore.

Frutos Balibrea, L. (2009). La igualdad y la desigualdad entre sexos en las Fuerzas Armadas. En M. Gómez, \& I. Sepúlveda (Eds.), Las mujeres militares en España (1988-2008) (pp. 253-284). Instituto Universitario General Gutiérrez Mellado.

Fuller, N. (1988). Tradiciones mantenidas, prácticas renovadas: crisis de la identidad femenina. Debates en Sociología, 12-14, 5-27.

Gaña, F. (2008). El asalto de las mujeres a las carreras universitarias "masculinas": cambio y continuidad en la discriminación de género. Praxis Educativa, 12, 77-86.

Giménez, G. (2007). Estudios sobre la cultura y las identidades sociales. Iteso.

Goldman, N. L. (1982). Female soldiers - Combatants or noncombatants? Historical and Contemporary. Greenwood Press.

Gómez Escarda, M. (2009). La mujer militar y la familia. En M. Gómez, \& I. Sepúlveda (Eds.), Las mujeres militares en España (1988-2008) (pp. 285-304). Instituto Universitario General Gutiérrez Mellado.

Gómez, A., \& Perdomo, I. (1993). El eterno femenino: hormonas, cerebro y diferencias sexuales. Arbor, 144(565), 109-140.

Grimson, A., (2010). Culture and identity: Two different notions. Social Identities, 16(1), 63-79.

Hall, S. (1996). ¿Quién necesita identidad? En S. Hall, \& P. Du Gay (Comps.), Cuestiones de identidad cultural Argentina. Amorrortu Editores.

Herbert, M. S. (1998). Camouflage isn't only for combat: Gender, sexuality, and women in the military. New York University Press.

Hong, D-S. (2002). Women in the South Korean Military. Current Sociology, 50(5), 729-743.

Höpfl, H. (2003). Becoming a (virile) member: Women and the military body. Body \& Society, 9(4), pp. 13-30.

Höpfl, Heather. (2000). Motivation. En E. Wilson (Ed.), Organizational behavior reassessed. Sage Publications.

Jayme Zaro, M. (1999). La identidad de género. Revista de Psicoterapia, 10(40), 5-22.

Jiménez, I. (2008). ¿Qué es esa cosa llamada lo femenino? Paradigma, 5, 7-8.

Kimmel, M. (1997). Homofobia, temor, vergüenza y silencio en la identidad masculina. En T. Valdés, \& J. Olavarría (Eds.), Masculinidadles: poder y crisis. Ediciones de las Mujeres No. 24. Isis Internacional/FLACSO-Chile.

King, A. (2013). Women in combat. The RUSI Journal, 158(1), 4-11. 
Lagarde, M. (2000). Claves feministas para la mejora de la autoestima. Horas y Horas.

Lagarde, M. (s. f.). Identidad femenina. https://bit.ly/3fCpGxR

Latorre, E. J., \& Fernández-Osorio, A. E. (2018). Innovación educativa para el fomento de la equidad de género en las Fuerzas Militares. En A. E. Fernández-Osorio, \& E. J. Latorre (Eds.), La construcción del rol de la mujer militar (141-161). Escuela Militar de Cadetes "General José María Córdova".

Laurence, J., Milavec, B., Rohall, D., Ender, M., \& Matthews, M. (2016). Predictors of support for women in military roles: Military status, gender, and political ideology, Military Psychology, 28(6), 488-497.

Lence Reija, C. (1995). La mujer en el ejército. Boletin de Información, 241, 45-59.

Londońo, L. M. (2005). La corporalidad de las guerreras: una mirada sobre las mujeres combatientes desde el cuerpo y el lenguaje. Revista de Estudios Sociales, 21, 67-74.

Lupano, M. L., Castro, A., \& Casullo, M. M. (2008). Prototipos de liderazgo masculino y femenino en población militar. Revista de Psicología, 26(2), 195-218.

Marcus, G. (2001). Etnografía en el sistema mundo. Surgimiento de la etnografía multilocal. Alteridades, 11(22), 111-127.

Martín Martínez, V. (2009). Las mujeres en los ejércitos europeos y americanos. En M. Gómez, \& I. Sepúlveda (Eds.), Las mujeres militares en España (1988-2008) (pp. 23-43). Instituto Universitario General Gutiérrez Mellado.

Martínez Cruz, A. (2016). Tejiendo identidades estratégicas: Asamblea de Mujeres Indígenas de Oaxaca. Nómadas, 45, 169-187.

Martínez Herrera, M. (2007). La construcción de la feminidad: la mujer como sujeto de la historia y como sujeto de deseo. Actualidades en Psicología, 21(108), 79-95.

Martínez, A. (1992). Identidad femenina: crisis y construcción. En M. L. Tarrés, La voluntad del ser. Mujeres en los noventa (pp. 65-84). Colegio de México.

Mateos Sillero, S. (2013). Construcción de la feminidad normativa y sujeto político. Investigaciones feministas, 4, 297-321.

Ministerio de Defensa. (2018). Política pública sectorial de transversalización del enfoque de género para el personal uniformado de la Fuerza Pública 2018-2027. https://bit.ly/2ANP0m1

Moore, B. (2017). Introduction to Armed Forces \& Society: Special issue om women in the military. Armed Forces \& Society, 43(2), 191-201. https://doi.org/10.1177/0095327X17694909

Moreno Orta, E. (2013). Los estudios de género y las transformaciones del imaginario social en las Fuerzas Armadas. Tecnologia e Sociedade, 9(18), 1-14.

Olavarría, J. (2007). Feminidad, cuerpo y género. Una mirada desde la sociología. Revista gpu, 3(4), 467-476.

ONU Mujeres. (2017). Mujeres militares. Historias de grandeza al servicio de la paz. Comando General de las Fuerzas Militares; onu Mujeres. https://www2.unwomen.org///media/field\%20 office $\% 20$ colombia/documentos/publicaciones/2017/03/mujeres $\% 20$ militares $\% 20$ web. pdf?la $=e s \& v s=4140$

Otálora Parra, M. C. (2015). Llevar el Ejército en el pecho. De cómo se aprende a ser militar en la Escuela Militar de Cadetes José María Córdoba [Tesis de pregrado]. Repositorio de la Pontificia Universidad Javeriana. https://repository.javeriana.edu.co/bitstream/handle/10554/21924/OtaloraParraMariaCamila2015. pdf?sequence $=1$ \&isAllowed $=y$ 
Palermo, A. (2006). El acceso de las mujeres a la educación universitaria. Revista Argentina de Sociología, $4(7), 11-46$.

Pérez Bravo, C. (2011). Una aproximación a la construcción de identidad de mujeres cadetes en la Escuela Militar del Ejército de Chile. Calidad en la Educación, 35, 165-192.

Portal Ariosa, M. A. (1991). La identidad como objeto de estudio de la antropología. Alteridades, 1(2), 3-5.

Ramos, A., Barberá, E., \& Sarrió, M. (2003). Mujeres directivas, espacio de poder y relaciones de género. Anuario de Psicología, 34(2), 267-278.

Rosen, L., Knudson, K., \& Fancher, P. (2003). Cohesion and the culture of hypermasculinity in U.S. army units. Armed Forces \& Society, 29(3), 325-351.

Saletti Cuesta, L. (2008). Propuestas teóricas feministas en relación al concepto de maternidad. Clepsydra, 7, 169-183.

San Miguel, M. (2015). Efectos en las subjetividades contemporáneas de la desigualdad y de las relaciones de poder entre los modelos de masculinidad y feminidad. En A. Hernando (Ed.), Mujeres, hombres, poder. Subjetividades en conflicto (pp. 151-181). Traficantes de Sueños.

Sánchez de Bustamante, M. (2014). Deseo, destino y devoción. La maternidad como esencia femenina en la revista Ser padres hoy. Question, 1(43), 343-355.

Sasson-Levy, O. (2003). Feminism and military gender practices: Israeli women soldiers in "masculine" roles. Sociological Inquiry, 73(3), 440-465.

Senabre Llabata, C. (2014). Claude Cahun: el tercer sexo o la/s identidad/es al desnudo. Dossiers Feministes, 18, 79-92.

Sieber, S. (1999). The deconstruction of gender as archetype in Rosario Castellanos' "El eterno femenino". Letras Femeninas, 25(1/2), 39-48.

Silva, J. (2008). A new generation of women? How female ROTC cadets negotiate the tension between masculine military culture and traditional feminity. Social Forces, 87(2), 937-960.

Titunik, R. (2000). The first wave: Gender integration and military culture. Armed Forces and Society, 26(2), 229-257.

Torres-Reyna, O., \& Shapiro, R. (2002). Trends: Women and sexual orientation in the Military. The Public Opinion Quarterly, 66(4), 618-632.

Tubert, S. (2010). Los ideales culturales de la feminidad y sus efectos sobre el cuerpo de las mujeres. Quaderns de Psicologia, 12(2), 161-174.

Valdés, T. (1995). Identidad femenina y transformación en América Latina: a modo de presentación. En L. G. Arango, M. León, \& M. Viveros (Comps.), Género e identidad. Ensayos sobre lo femenino y lo masculino. Ediciones Uniandes; Universidad Nacional de Colombia; Tercer Mundo Editores.

Wills, M. E. (2005). Mujeres en armas: ‘avance ciudadano o subyugación femenina? Análisis politico, 18(54), 63-80.

Zubieta, E., Beramendi, M., Sosa, F., \& Torres, J. A. (2011). Sexismo ambivalente, estereotipos y valores en el ámbito militar. Revista de Psicología, 29(1), 101-130.

Zuluaga Ramírez, D. (2016). Inclusión de la mujer militar en el campo de combate una perspectiva de género [Tesis de maestría]. Universidad Militar Nueva Granada, Bogotá. 